\title{
De betelenis van internationale organisaties in het accountantsberoep
}

Prof. Drs. G.G.M. Bak

\section{Inleiding}

Voor een beschouwing omtrent de betekenis van internationale beroepsorganisaties biedt de maand oktober 1992 een aantal aanknopingspunten. Deze aanknopingspunten geven tevens de thema's aan die in dit artikel aan de orde zullen komen

- Het $14 \mathrm{e}$ Wereldcongres van accountants in Washington geeft aanleiding wat nader in te gaan op de rol van IFAC (een lijst met afkortingen en hun betekenis is opgenomen aan het slot van dit artikel) in het leven van de individuele accountant.

- Het verschijnen van de gebonden uitgave 'IFAC Handbook 1992, Technical Pronouncements' richt de aandacht op de inhoudelijke betekenis van vaktechnische literatuur afkomstig van IFAC en IASC

- De aanvaarding door IOSCO van de IAPCstandaarden vraagt om commentaar op de in stitutionele betekenis van het werk van IFAC en IASC.

\section{IFAC, IASC en de individuele accountant}

ledere 5 jaar wordt een Wereldcongres georganiseerd voor accountants, aangesloten bij de instituten en organisaties die gezamenlijk pretenderen het accountantsberoep te omvatten. Het IFAC handboek 1992 vermeldt trots dat het daarbij gaat om 'more than 1.000 .000 accountants in public and private practice, education and government service'. De aanwezigheid van slechts een kleine 2000 accountants tijdens het $14 \mathrm{e}$ Congres in Washington DC geeft reeds aan dat van een hechte, emotioneel beleefde band tussen 1 miljoen vakbroeders en -zus- ters geen sprake is. Dit beeld wordt nog helderder als men de regelmatige teruggang in het congresbezoek waarneemt. Zich baserend op congressen in de jaren zeventig (Sydney 1972. München 1977) rekenen de organisatoren nog altijd op een opkomst van 5 a 6000 accountants. Het congresbezoek is sinds die topjaren echter voortdurend blijven dalen. Het lijkt erop dat zich internationaal hetzelfde dilemma aftekent als nationaal: de belevingswereld van de individuele accountant wordt vooral bepaald door zijn kantoor, werksituatie en functie. In die omgeving is er doorgaans ruimschoots gelegenheid vakgenoten te ontmoeten. Sinds de opkomst van de internationale werkverbanden tussen accountants heeft een internationale beroepsorganisatie als zodanig weinig toegevoegde waarde te bieden aan de individuele accountant. Ongetwijfeld vormt deze statistiek van bezoekersaantallen voor de bestuurders een aansporing zich eens te bezinnen op functie en formule van deze congressen. Vermeden moet immers worden dat de congressen te eenzijdig het karakter krijgen van samenkomst van 'gezagsdragers', bestuursleden, officials van de aangesloten organisaties. Ook in het beroepsleven van alledag kan niet gezegd worden dat IFAC en IASC individuele accountants het gevoel geven dat zij tot één wereld-omspannende beroepsgroep behoren. Ter vermijding van misverstand: persoonlijk acht ik zulks ook niet een doelstelling die behoort te worden

Prof. Drs. G.G.M. Bak, registeraccountant, is hoogleraar Accountancy aan de KUB en vennoot Coopers \& Lybrand Dijker Van Dien. Gedurende de jaren 1978-1989 vervulde hij diverse functies als NIvRA-vertegenwoordiger in IFAC. Van 1983-1985 was hij voorzitter van IAPC. Thans is hij Buitengewoon Raadadviseur van de minister van Justitie in jaarrekeningenzaken, alsmede Nederlands vertegenwoordiger bij de Verenigde Naties en OESO terzake van Verslaggevingsvraagstukken. 
nagestreefd. Dit soort wereldomspannende organisaties dient veeleer te worden beoordeeld naar de mate waarin zij de belangen van het beroep op internationaal niveau behartigen. Dit geschiedt in eerste instantie door het bepalen van het 'gezicht' van het beroep tegenover soortgelijke organisaties van andere beroepen, overheden, toezichthouders en dergelijke. Daartoe is dan ook gekozen voor een getrapte organisatievorm: niet individuele accountants zijn lid, het betreft federaties van de aangesloten landelijke beroepsorganisaties.

\section{IFAC Handbook, inhoudelijke betekenis van richtlijnen}

Een geheel ander niveau van waarneming levert het werk op dat wordt gedaan door beroepsgenoten in commissies en werkgroepen van IFAC en IASC. Het resultaat van 15 a 20 jaar commissiewerk is onlangs op handzame wijze beschikbaar gekomen in het IFAC Handbook, dat periodiek (jaarlijks) in bijgewerkte vorm zal worden uitgegeven tegen een abonnementsgeld van $\$ 200$ per jaar.

Het IFAC Handbook 1992 beslaat 1060 pagina's waarin zijn opgenomen:

aantal pagina's

Standards/Statements on auditing

(controle-richtlijnen)

Accounting Standards

(normen voor de jaarverslaggeving)

Code of Ethics

(gedragsregels)

Public Sector pronouncements

(overheidsaccountancy)

Guidelines on Education

(opleidingsrichtlijnen)

Statements on Financial and

Management accounting

(bedrijfseconomische studies)
Uit de weergave in het IFAC Handboek valt alleen voor de zorgvuldige lezer op te maken dat de accounting standards afkomstig zijn van een ander lichaam dan de overige richtlijnen. Het IASC vormt immers een zelfstandig orgaan met een eigen 'Consultative Group'. Organisatorisch en qua lidmaatschap zijn IFAC en IASC echter nauw aan elkaar verbonden. Achter deze presentatie gaat een nauwelijks te onderdrukken neiging schuil van IFAC-bestuurders uit Angelsaksische kring om de regelgeving terzake van de jaarverslaggeving tot de taak van het accountantsberoep te rekenen. Tot op heden is - mede door de opstelling van het NIvRA - de scheiding tussen IFAC en IASC steeds in stand gehouden als erkenning dat ook andere maatschappelijke groeperingen dan accountants betrokken behoren te worden bij regelgeving omtrent financiële verslaggeving. Regelgeving terzake van de accountantscontrole en 'ethiek' behoren veel meer tot het terrein van het accountantsberoep in engere zin, zoals internationaal gerepresenteerd door IFAC.

Het bestek van dit artikel laat uiteraard niet toe dat op de inhoud van al deze richtlijnen en standaarden wordt ingegaan. In het algemeen valt waar te nemen dat IFAC en IASC niet voorop lopen in ontwikkelingen, maar meer consoliderend te werk zijn gegaan. In de fase waarin dit alles tot stand is gekomen lijkt het ook verstandig dat in eerste instantie is getracht het gehele veld van de accountantspraktijk in kaart te brengen. Waar verschillen tussen landen bestaan zijn zij veelal terug te voeren op vaak diepgaande verschillen in cultuur, traditie, rechtsstelsel en dergelijke. Het zou van weinig wijsheid getuigen, deze verschillen van meet af aan te willen overbruggen door het stellen van normen op wereldniveau. Dit alles brengt uiteraard met zich mee dat de richtlijnen en standaarden veelal weinig nieuws bevatten voor de accountants in landen waar het beroep reeds een hoog niveau van ontwikkeling heeft bereikt. Waar tussen die landen belangrijke verschillen bestaan worden die veelal weerspiegeld in de opties die IFAC en IASC terzake openlaten. Voor landen waar het accountantsberoep nog in een ontwikkelingsfase verkeert is de inhoud van het IFAC Handboek van groot praktisch belang. Veel ontwikkelingslanden hebben de IFAC-richtlijnen geheel of ten dele overgenomen. Andere landen heb- 


\section{MAB}

ben hun eigen proces van ontwikkeling parallel laten lopen aan wat binnen IFAC gebeurde. Zo hebben de Australische beroepsorganisaties lange tijd de ontwerpen ter discussie afkomstig van IAPC in eigen kring voor commentaar verspreid.

Dit commentaar werd gevraagd op 2 niveaus:

- als ontwerp voor een internationale richtlijn;

- als ontwerp voor eigen regelgeving.

Op basis van dit laatste werden de Australische controlerichtlijnen vervolgens vastgesteld. Uiteraard is zo'n werkwijze eenvoudiger te volgen voor een Engelstalig land dat bovendien sterk onder Engelse invloed heeft gestaan, dan in bijvoorbeeld de continentaal Europese landen waar aanzienlijk meer culturele en institutionele afstand moet worden overbrugd. In Nederland zijn het NIvRA en de RJ dan ook veel meer afstandelijk te werk gegaan. Het is een goede gewoonte geworden in richtlijnen en beschouwingen aan te geven dat daarbij de internationale standaarden van IFAC en IASC in aanmerking zijn genomen. De RJ geeft zelfs uitdrukkelijk aan op welke punten IASC niet is gevolgd (RJ bijlage 6 bundel t/m 1989).

Persoonlijk is mij vaak opgevallen dat er op de vermeende overeenstemming tussen internationale en Nederlandse richtlijnen nogal eens wat valt af te dingen. Dit manifesteert zich vooral indien een $\mathrm{Ne}$ derlandse vertaling wordt gehanteerd, zoals de overigens zeer verdienstelijke - vertaling van het IASC-Conceptual Framework die onder de titel Stramien in de RJ-bundel is opgenomen (RJS - 01 e.v.). Vele begrippen die hier worden gehanteerd zijn niet of slechts met moeite terug te vinden in de RJrichtlijnen. Nog sterker kwam dit naar voren toen het NIvRA het fenomeen 'audit related services' introduceerde door - volgens Australisch recept - een letterlijke vertaling van de desbetreffende IAPCrichtlijnen als ontwerp ter discussie aan het Nederlandse accountantsberoep aan te bieden. Voor velen bleek wat in het Engels aannemelijk klonk in het Nederlands als wartaal over te komen. Er was een ingrijpende bewerking nodig om althans een begrijpelijke tekst tot stand te brengen op basis waarvan over de vaktechnische merites verder kon worden gediscussieerd.

Door de zorg van de regionale of landelijke beroepsorganisaties zijn er van de meeste IFAC en
IASC-richtlijnen vertalingen in een groot aantal talen tot stand gebracht, waardoor de verspreiding uiteraard verder wordt bevorderd. In Nederland is aanvankelijk een systematische vertaling opgebouwd van de IASC-Standards. Later is daarvan afgezien omdat Nederlandse beroepsgenoten voldoende taalvaardigheid wordt toegedacht om zich van de originele Engelse tekst te kunnen bedienen.

Samenvattend ligt de inhoudelijke betekenis van de IFAC/IASC literatuur vooral in de weergave van 'the state of the art' op internationaal niveau. Het accountantsberoep heeft zich - in het zicht van de snel voortschrijdende internationalisatie - uitermate slagvaardig betoond door in betrekkelijk korte tijd deze weergave tot stand te brengen. Daarbij passen op deze plaats twee bespiegelingen:

- De Nederlandse inbreng in dit werk is van substantiële betekenis geweest. NIvRA heeft zich van meet af geschaard bij de oprichters van IASC en van IFAC en daadwerkelijk bijgedragen aan het commissiewerk. Zonder anderen te kort te willen doen acht ik het gepast hier de namen te vermelden van Tempelaar, nauw betrokken bij het tot stand komen van beide organisaties en van Burggraaf, die als IASC-voorzitter een belangrijke rol speelde bij de verbreding van het draagvlak tot vertegenwoordigers van andere maatschappelijke groeperingen in de reeds genoemde 'Consultative Group'. Voorts is uiteraard de rol van Volten niet weg te denken bij een analyse van de Nederlandse inbreng in internationaal verband. Het NIvRA opereerde niet alleen vaktechnisch maar ook 'politiek' op professioneel niveau, dank zij 'Ambassadeur Volten'.

- Een tweede bespiegeling betreft de betrekkelijkheid van meer dan 1000 pagina's vaktechnische literatuur. Het belang daarvan wordt pas echt duidelijk bij de implementatie. Daarop wordt in het derde gedeelte van dit artikel ingegaan.

\section{IOSCO - Implementatiefase?}

Het IFAC Handboek ontleent zijn autoriteit vooral aan de inherente kwaliteit van de inhoud. Parafraserend op de rol van de RJ-richtlijnen bij de rechtspraak in de Ondernemingskamer in Nederland, kan het worden beschouwd als 'gezaghebbende literatuur'. De 
leden-organisaties hebben zich verplicht het redelijke te doen om de IFAC en IASC standaarden en richtlijnen te doen opnemen in de lokale regelgeving. Wie kennis neemt van de overzichten die van tijd tot tijd vanwege IFAC worden vervaardigd krijgt de indruk dat de implementatie succesvol verloopt. Een wat meer kritische analyse geeft echter aan hoe schijn kan bedriegen:

- de overzichten berusten op opgaven van de deelnemende organisaties; niet op feitelijk onderzoek;

- gezien het compromissoire karakter van de standaarden en richtlijnen (vele opties) betekent naleving ervan nog geen harmonisatie, laat staan uniformering;

- het overgrote deel van de literatuur bevat richtlijnen die zo vanzelfsprekend, of zo algemeen geformuleerd zijn dat het moeilijk lijkt er niet aan te voldoen.

De werkelijke betekenis van internationale beroepsorganisaties blijkt dan ook pas als zij in de vuurlinie terechtkomen bij controversiële onderwerpen. En wat dan blijkt is dat er nog maar weinig harmoniserende kracht uitgaat van het IFAC Handboek. In eerste instantie wordt geprobeerd de angel uit het probleem te halen tijdens het tot stand komen. Hieruit komt het compromiskarakter voort dat hiervoor reeds werd onderkend. In tweede instantie schromen de ledenorganisaties niet om zich te beroepen op de 'best endeavor'-clausule, of zelfs zonder meer van implementatie af te zien.

Zo heeft het in Nederland ruim 7 jaar geduurd voordat het NIvRA de aanbevolen bewoordingen van de accountantsverklaring en de te onderscheiden strekkingen daarvan enigszins heeft aangepast aan de inhoud van IAG 13 'The audit report', dat reeds in 1983 door IAPC is gepubliceerd. Anekdotisch is in dit verband het feit dat de desbetreffende richtlijn zelfs niet werd opgenomen in de daartoe bestemde reeks in de zogenaamde RADAR-bundel. De registeraccountant werd afgescheept met een titelblad waarop in een zwart kadertje werd vermeld dat opname in de bundel niet opportuun werd geacht nu NIvRA tegen vaststelling van de richtlijn heeft gestemd. Een methodiek die gekopieerd lijkt van de zogenaamde Index zoals die in de Katholieke Kerk gebruikelijk was om het kerkvolk te behoeden voor slechte invloeden. Men kan dus betwijfelen of de lokale beroepsorganisatie en a fortiori de individuele beroepsbeoefenaar uiteindelijk bereid zal blijken de praktijkuitoefening ook ten aanzien van kritische en controversiële punten af te stemmen op het IFAC Handboek. Zoals in het eerste gedeelte van dit artikel aangegeven kunnen de 'meer dan 1.000.000 accountants' wereldwijd zeker niet als een hechte en coherente groep worden aangemerkt. Op eigen kracht zal werkelijke harmonisatie slechts uiterst langzaam tot stand komen. Er zal druk van buiten nodig zijn om te bewerkstelligen dat de rijen zich sluiten!

In dit verband is het van betekenis melding te maken van mijn observaties als Nederlands vertegenwoordiger in de werkgroepen op het gebied van financiële verslaggeving binnen de VERENIGDE NATIES (ISAR) en OESO. Hier wordt op het niveau van de overheid een platform gevormd voor overleg terzake van regelgeving rond 'accounting en auditing'. Ondanks vaak hartige kritiek leeft daar vrij algemeen de gedachte dat de standaarden en richtlijnen van IASC en IFAC belangrijke bouwstenen vormen voor het harmonisatieproces op wereldniveau.

De eerste internationale organisatie die op deze wijze van IASC en IFAC gebruik wil maken is IOSCO. Het initiatief dat IOSCO in 1987 nam om te streven naar endossering van de standaarden van IASC en IAPC (respectievelijk terzake van financiële verslaggeving en accountantscontrole) kan worden beschouwd als een belangrijke doorbraak. In het financiële en effectenverkeer waar internationalisatie het snelst doorzet en harmonisatie het hardst nodig is blijkt het commissiewerk van de afgelopen decennia nu reeds zijn vruchten af te werpen. De overkoepelende organisatie van toezichthouders op het effectenverkeer besluit in beginsel op het stuk van financiële verslaggeving geen eigen regels op te stellen maar gebruik te maken van wat binnen het beroep reeds tot stand werd gebracht. Onder het motto 'alles heeft zijn prijs' heeft IOSCO wel een aantal voorwaarden gesteld, die moesten leiden tot aanpassingen in de voorliggende teksten.

Wat IAPC betreft zijn deze aanpassingen inmiddels nagenoeg geheel aangebracht, zodat in oktober 1992 het definitieve besluit kon worden genomen (FT 1992). IOSCO beschouwt de IAPC standaarden 
als 'most suited to the purpose of determining a set of generally accepted international auditing standards'.

De aanpassingen die door IOSCO werden verlangd ten opzichte van de bestaande IAG's waren weinig controversieel van aard. Veelal ging het om nadere detaillering van richtlijnen die te algemeen en vaag waren geformuleerd. Anekdotisch grappig is het verlangen terzake van de accountantsverklaring bij dreigende continuiteitsproblemen. Met een beroep op US-GAAS wijst IOSCO het hanteren van een qualified opinion in zo'n situatie af; er moet een goedkeurende verklaring komen met een 'explanatory paragraph: IAG 13 zou in 1983 reeds op die wijze zijn geformuleerd, ware het niet dat de US delegatie destijds - met een beroep op de toenmalige US-GAAS - die weg met klem afwees.

Ten aanzien van de IASC-standaarden is het gesprek met IOSCO nog niet afgerond. Een belangrijke stap in deze ontwikkeling was de publikatie in juli 1990 van 'Statement of Intent, Comparability of Financial Statements', gebaseerd op een ontwerp ter discussie van januari 1989 (ED 32). IASC doet blijkens dit 'Statement of Intent' verwoede pogingen aan de verlangens van IOSCO tegemoet te komen Opties worden geschrapt of vervangen door het aanwijzen van een voorkeursmethode (preferred treatment) naast alternatieven, die derhalve de facto door IASC worden afgeraden.

Bij een andere gelegenheid heb ik mij al eens kritisch uitgelaten over de door IASC op dit punt gevolgde werkwijze (Bak 1990). De keuzen die worden gemaakt maken op de geïnteresseerde buitenstaander een nogal willekeurige indruk. De door IASC uitgesproken voorkeuren lijken meer gebaseerd op het stemgedrag van de leden dan op een consistente gedachtengang. Een gemiste kans - naar mijn oordeel - om het tezelfdertijd geformuleerde 'conceptual framework' te verankeren in het proces van regelgeving. In eerder genoemde publikatie gaf ik twee voorbeelden ter illustratie:

- het afwijzen van de LIFO-methode bij voorraadwaardering

Er ligt een verband tussen de LIFO-methode en een substantialistische benadering van vermogen en winst. Het gaat dus niet aan deze methode te verbieden zonder expliciet te stellen dat hiermee afstand wordt genomen van het physical concept of capital maintenance' (zoals in het Conceptual framework uiteengezet (zie paragraaf 102 e.v., IFAC-Handboek p.785 e.v.)). Dat de discussie hierover weer is opgelaaid vindt niet zijn oorzaak in nadere bezinning op het conceptual framework, maar veeleer in de vraag of belangrijke landen als USA op dit punt IASC zullen volgen:

- de voorkeur voor het niet activeren van ontwikkelingskosten

Het enige argument dat deze voorkeur moet dragen is de voorzichtigheid (prudence). Vóór activeren van ontwikkelingskosten pleit uiteraard dat daardoor een betere 'matching' van kosten en opbrengsten ontstaat zodat het inzicht (relevance) wordt gediend.

De afweging die IASC hier maakt tussen 'prudence' en 'relevance' volgt geenszins uit de afweging zoals die in het conceptual framework in algemene zin wordt gemaakt. (Zie paragraaf 37,IFAC-Handboek p. 773 e.v.) Daaruit zou men eerder het omgekeerde afleiden.

Het belang van deze kritiek moet vooral worden gezien in het licht van de positie die IASC in politieke zin inneemt. Hoewel de steun in de rug van IOSCO uiteraard grote betekenis heeft komt IASC met dit Statement of Intent duidelijk in woelig politiek vaarwater terecht. De innerlijke consistentie van de standaarden, gebouwd op een duidelijk herkenbaar 'Stramien', acht ik van grote betekenis om daarin stand te houden.

De politieke dimensie aan het werk van IASC tekent zich steeds duidelijker af. Wie kennis neemt van het recente artikel van Van Hulle in het MAB (Van Hulle, 1992) kan daaruit de kansen en valkuilen voor IASC aflezen. In het kort kunnen zij als volgt worden samengevat:

IASC wordt weliswaar erkend als regelgever zonder bindende autoriteit. maar bevindt zich in het spanningsveld tussen het Angelsaksische en het Continentaal Europese denken. Protagonisten van beide stromingen zijn aan de ene kant de USA (SECFASB) en aan de andere kant de EEG (RichtlijnenForum). In de beleving van EEG wordt IASC in ster- 
ke mate vereenzelvigd met de Amerikaanse benadering van de financiële verslaggeving. Dit is overigens een opmerkelijk verschijnsel gezien de sterke Europese vertegenwoordiging (Duitsland, Frankrijk, Nederland, Engeland) die vanaf de oprichting in IASC heeft geopereerd. Hoe dit zij, de tegenstelling EEG-USA manifesteert zich met name op het vlak van wederzijdse erkenning, in het bijzonder terzake van beursnotering in de USA en het is zeer de vraag of IASC hierin een bemiddelende rol kan spelen. Het artikel van Van der Wel - opgenomen in dit MABnummer - maakt gewag van het verzet in Nederland bij grote ondernemingen en binnen de $\mathrm{RJ}$ tegen de voornemens van IASC. In de internationale arena laat ook Duitsland bijvoorbeeld duidelijk blijken de toenadering tussen IASC en IOSCO met zorg te volgen. Men is aldaar bevreesd dat via de effectenbeurzen regelgeving wordt afgedwongen die op essentiële punten afwijkt van de Duitse wetgeving, zoals gebaseerd op de Vierde en Zevende Richtlijn EEG. Over de aard van die afwijkingen maakt men zich weinig illusies: die zijn in hoge mate geïnspireerd op de Amerikaanse regelgeving (FASB). In dat verband is het interessant te zien hoe Prof. van Hulle als EEG-belanghebbende in opgemeld MAB-artikel internationale ondernemingen aan de kaak stelt die de IASC-normen voorrang lijken te geven boven de wettelijke - op EEG-richtlijnen gebaseerde - vereisten voor de financiële verslaggeving.

Behalve een deugdelijk vaktechnisch fundament zal IASC nog veel stuurmanskunst moeten tonen om in dit politiek vaarwater niet op de klippen te lopen. Een bemoedigend geluid komt in elk geval uit $\mathrm{Ne}$ derland en wel in de vorm van onderstaand citaat uit de Memorie van Toelichting bij het wetsontwerp 'Bepalingen voor de jaarrekening van verzekeringsmaatschappijen', dat onlangs bij de Tweede Kamer is ingediend ( $\mathrm{Nr}$. 22896). Weergave van dit citaat lijkt mij een goed besluit van dit artikel:

'Met de totstandkoming van de richtlijn (geconsolideerde) jaarrekening verzekeringsmaatschappijen is de basisharmonisatie van het jaarrekeningrecht voltooid. Internationaal, in het kader van het International Accounting Standards Committee (IASC), wordt intussen naar verdere harmonisatie van de verslaggevingsregels in het algemeen gestreefd door te komen tot een vermindering van de thans nog omvangrijke keuzemogelijkheden voor de weergave van de financiële positie. Dit streven wordt mede ingegeven door de wens tot verdere harmonisatie van de jaarrekeningvoorschriften voor beursgenoteerde ondernemingen. Het IASC is een particuliere organisatie op wereldniveau van nationale accountantsorganisaties die op een veel uitgebreidere wijze dan thans in de Nederlandse regelgeving, jaarrekeningvoorschriften formuleert. Deze voorschriften binden formeel niet.

Vermindering van keuzemogelijkheden bevordert de vergelijkbaarheid van de informatie. Dat kan soms ten koste gaan van een betrouwbaar inzicht in de financiële positie. Het streven naar vermindering van de keuzemogelijkheden in het licht van een betere vergelijkbaarheid, maar zonder het doel van het verschaffen van een betrouwbaar inzicht in de financiële positie van een rechtspersoon uit het oog te verliezen, is, gelet op de grote verschillen in tradities op dit terrein, geen eenvoudige zaak. Een poging om eerst via de weg van niet formeel bindende 'standaarden' tot verdere harmonisatie te komen, verdient evenwel alle steun.'

\section{Afkortingen}

(in volgorde van eerste gebruik in dit artikel)

IFAC International Federation of Accountants (sinds 1977), waarbij aangesloten de volgende regionale organisaties:

IAA Amerikaanse Continent

CAPA Azië en Pacific

FEE Europa.

IASC International Accounting Standards Committee (sinds 1973).

IOSCO International Organisation of Security Commissions.

IAPC International Audit Practices Commit tee.

IAG International Audit Guideline, opgesteld en gepubliceerd door IAPC (inmiddels aangeduid als 'Standards').

US-GAAS Generally Accepted Auditing Standards in USA. 
ISAR International Studygroup of Accounting and Reporting - VERENIGDE NATIES.

ED Exposure Draft, Ontwerp ter discussie. LIFO Last in First out, een methode waardoor bij stijgende prijzen de actuele waarde van het goederenverbruik in de resultatenrekening wordt benaderd.

\section{Literatuur}

Bak, G.G.M., Enkele beschouwingen over werkwijze en positie van IASC, opgenomen in Vergelijkbaarheid van Jaarrekeningen in nationaal en internationaal perspectief, Deventer, Kluwer Bedrijfswetenschappen 1990.

FT, Financial Times 30 oktober 1992, Verslag IOSCOconference.

Hulle, K.van, Harmonisatie van de regels inzake financiële verslaggeving, MAB, september 1992 pp. 400 e.v.

IFAC, Handbook 1992, Technical Pronouncements, International Federation of Accountants, New York.

Raad voor de Jaarverslaggeving (RJ), Richtlijnen voor de Jaarverslaggeving. Kluwer Deventer, losbladig.

Wel, F. van der, Internationalisatie van de Nederlandse jaarverslaggeving, $M A B$, december1992, pp.584. 